Journal of Advanced Research in Fluid Mechanics and Thermal Sciences

Journal homepage: www.akademiabaru.com/arfmts.html ISSN: 2289-7879

\title{
Analysing Hydraulic Efficiency of Water Vortex Pico-Hydro Turbine using Numerical Method
}

\author{
Ridho Irwansyah ${ }^{1,}{ }^{*}$, Warjito $^{1}$, Budiarso $^{1}$, Christopher Clement Rusli ${ }^{1}$, Sanjaya BS Nasution ${ }^{1}$ \\ Department of Mechanical Engineering, Faculty of Engineering, Universitas Indonesia, Depok 16424, West Java, Indonesia
}

\section{ARTICLE INFO \\ ABSTRACT}

\section{Article history:}

Received 18 July 2020

Received in revised form 23 August 2020

Accepted 24 August 2020

Available online 11 November 2020

Keywords:

CFD; Pico-Hydro; Vortex Blades; Vortex

Turbines

\begin{abstract}
To overcome the lack of rural electricity in Indonesia vortex pico-hydro turbines are used as an option solution. This is due to the ability of the vortex turbine to work in low head conditions effectively. This study is conducted with comparison of curved and straight blade to obtain a more optimum turbine performance. Two methods are carried out in this study, analytical and computational method. Analytical methods are used to determine blade geometry and its performance while computational methods are used to analyse internal flow of turbine. As a result, the study concludes that hydraulic efficiency of vortex turbine in this study doesn't affect much between straight and curved blades. The hydraulic efficiency for those blades is around 0.63 . In addition, the study continued by analysing the optimum location of the blade in the basin. The results of the study show that the optimum ratio of depth and diameter of the blade is 0.33 with turbine efficiency is 0.84 . Thus, the location of the blades is more important than the type of blades.
\end{abstract}

\section{Introduction}

Indonesia is an archipelago which causes a poor electrification ratio in remote areas. According to the statistics, the lowest electrification ratio is in NTT with only $62 \%$ of electrification in this area [15]. There are four main reasons which cause the difficulties of fulfilled electrification in remote areas. First, the population in remote areas is relatively small under 150 people, and they live scattered around. Second, access to the location is inadequate, which makes it difficult to reach with transportation. Third, the economy incomes are relatively small because the main occupation is farmers, fishermen, or home industries. Lastly, the demand for electricity is really low, which causes the capital price to distribute electricity is too expensive compared to consumption. To overcome this, a pico-hydro power plant is one of the solutions to generate electricity in remote areas of developing countries due to its easy manufactured, low investments and operating costs compared

\footnotetext{
* Corresponding author.

E-mail address: ridho.irwansyah04@ui.ac.id
}

https://doi.org/10.37934/arfmts.77.2.91101 
to other sustainable energy technology $[6,13]$. Moreover, Indonesia has a large hydropower potential of around 19.4 GW [7].

Pico-hydro power plants can generate a maximum output power of $5 \mathrm{~kW}$. Many kinds of turbines can be used as a hydropower plant. However, gravitational vortex hydropower plant (GVHP) is one of the turbines which works effective enough in low-head and low-flow condition [11]. One of the important factors which affect GVHP efficiency is the channel and basin [10].

In the previous work, the most efficient channel and basin had been analyzed with a numerical study, which showed the conical basin is the most suitable for GVHP. There have been many studies about the channel and basin for GVHP. Dhakal et al., [4] studied several geometric parameters for conical basin design and their effects on vortex formation and energy, which greatly affects the velocity and sensitivity of many other parameters. Timilsina et al., [16] tested 12 of variation in the basic design to analyze the circulation strength. Shabara et al., [14] used computational fluid dynamics (CFD) to investigate the optimum basin geometries, which showed an increasing velocity if the outlet diameter reduced and the water depth increased. There are also several studies about the blade configuration for GVHP. Dhakal et al., [3] compared the vortex strength of a cylindrical basin with a conical basin. This study concluded that the conical basin achieved a better vortex strength. Also, the best position to put the blade is near the outlet [3]. Marian et al., [9] experimented with many different conical basins and found the correlation of Froude's number, Weber's number, and Reynold's number with flow coefficient [9]. Khan [8] did a numerical and also experimental study using a cylindrical basin. His study shows the efficiency of four different blades and also the correlation of others parameter to vortex height. In this study, the best type of blade was achieved using a crossflow type of blade. This study also shows that the curved blade was worse than the inverted straight conical blade [8]. Ullah et al., [17] researched about the effect of multi-stage gravitational water vortex turbine in a conical basin. In his study, it showed the output parameters of shaft power (W), torque (N.m), and rotational speed (rpm) of single stage water vortex turbine with difference height condition which called T/D in my study. In his study, he used four conditions of T/D; a third of the blade in contact with the vortex, two over three of the blades in contact with the vortex, all the blade in contact with the vortex, and lastly the blade is a third submerged from the vortex surface. His study shows that the best output parameters occurred in the condition where all the blade in contact with the vortex which the blade surface is at the same height of the vortex surface [17].

There are already many papers that discussed the basin configuration. However, the discussion about blade configuration and the analytical method to decide the configuration haven't been discussed much. Because of that, this study aims is to show the analytical method used for designing the curved blade configuration, and to approximate the hydraulic efficiency of the blade, also optimizing the hydraulic efficiency using numerical method.

\section{Methodology}

\subsection{Analytical Method}

The channel used for this study was given from the previous work [2]. The parameters of this channel can be seen in Table 1. Figure 1 visualizes the channel and basin geometry used for this study. 


\section{Table 1}

Parameters Value of the Channel and Basin

\begin{tabular}{ll}
\hline Parameter & Value \\
\hline Basin Diameter $\left(D_{\text {eff }}\right)$ & $100 \mathrm{~mm}$ \\
Orifice Diameter $(d)$ & $30 \mathrm{~mm}$ \\
Approach flow angle $(\alpha)$ & $40^{\circ}$ \\
Inlet Height $\left(\boldsymbol{h}_{\text {in }}\right)$ & $33.33 \mathrm{~mm}$ \\
Channel Inlet $(L)$ & $100 \mathrm{~mm}$ \\
Minimal Conical Height $\left(\boldsymbol{h}_{\boldsymbol{d}}\right)$ & $20 \mathrm{~mm}$ \\
Conical Height $\left(\boldsymbol{h}_{\boldsymbol{d}}\right)$ & $70 \mathrm{~mm}$ \\
\hline
\end{tabular}
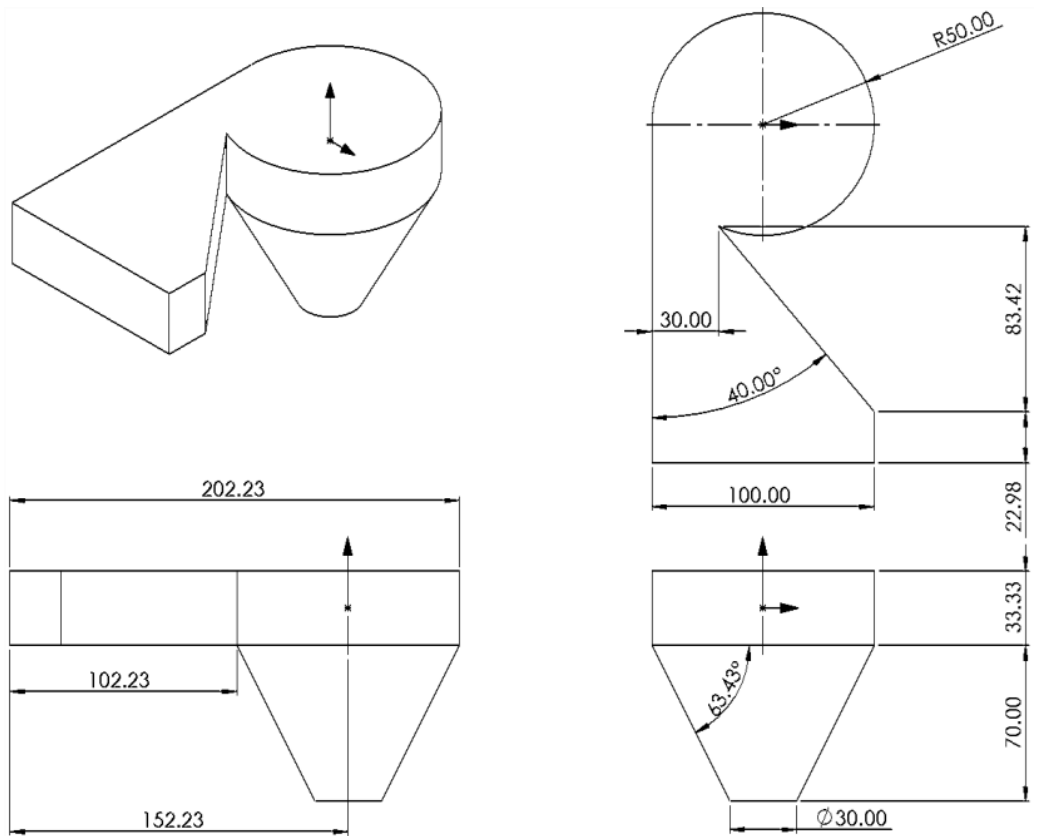

Fig. 1. Geometry of basin

The velocity triangle was being used for designing straight and curved blades. The analytical method for the curved blade is adopted from the analytic method from Francis turbine. Moreover, the straight blade analytical method is adopted by Kueh et al., [1]. Figure 2(a) and Figure 2(b) are velocity triangles for the curved blade and straight blade. Then, the equation for all of the parameters is given by Eq. (1)-(9).

$V_{\text {in }}=\frac{Q}{A_{\text {nozzle }}}$

$\frac{V_{\text {in }}}{\partial r}=\frac{C_{x 1}}{\partial r}$

$\frac{V_{\text {in }}}{\ln \left(r_{\text {basin }}\right)-\ln \left(r_{\text {oriface }}\right)}=\frac{C_{x 1}}{\ln \left(r_{\text {tip }}\right)-\ln \left(r_{\text {hub }}\right)}$

$C_{r 1}=\frac{Q}{2 \pi r_{t i p} b}$

$C_{r 2}=\frac{Q}{2 \pi r_{h u b^{b}}}$

$U_{1}=\frac{\pi N D_{t}}{60} \rightarrow$ Assume $N=250 \mathrm{rpm}$ 
$U_{2}=\frac{\pi N D_{h}}{60} \rightarrow$ Assume $N=250 \mathrm{rpm}$

$\tan \alpha_{1}=\frac{C_{r 1}}{C_{x 1}}$

$\tan \beta_{1}=\frac{C_{r 1}}{U_{1}-C_{x 1}}$

$\tan \beta_{2}=\frac{C_{r 2}}{U_{2}}$

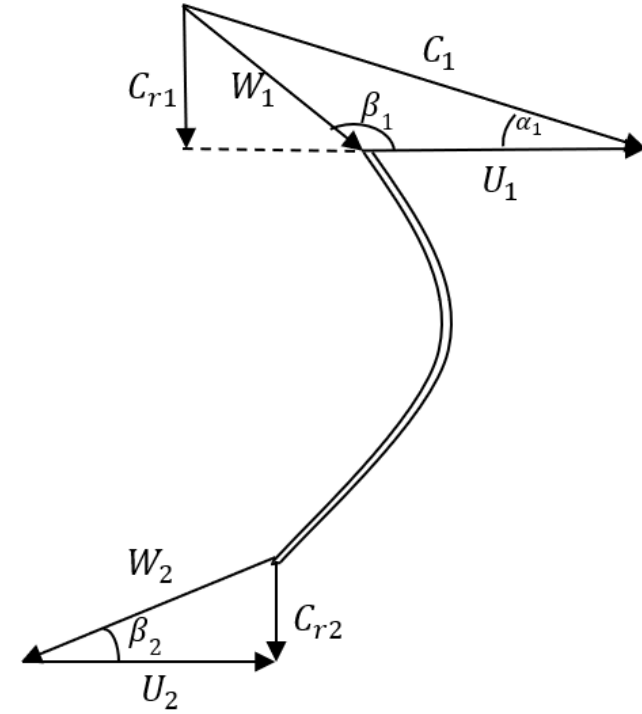

(a)

\section{Top View \\ @inlet}

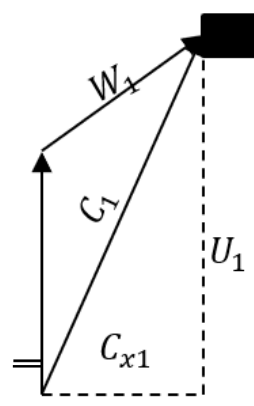

(b)
Side View

@outlet

Fig. 2. (a) Velocity Triangle for Curved Blade, (b) Velocity Triangle for Straight Blade [1]

After all the velocity parameters found, the Angle for the curved blade can be calculated; thus, the curved blade can be designed. The velocity parameters also used for calculating the approximate hydraulic efficiency of the curved blade given by Eq. (10)-(12).

$P_{\text {in }}=\frac{1}{2} \rho A V^{3}$

$P_{\text {out }}=\tau \omega$

$P_{\text {out }}=\dot{m}\left(U_{1} C_{x 1}-U_{2} C_{x 2}\right)$

$\eta_{H}=\frac{P_{\text {out }}}{P_{\text {in }}} \times 100 \%$

\subsection{Numerical Method}

The simulation of this study is carried out using Computational Fluid Dynamics (CFD) software (Ansys Fluent 18.1). First, the geometry for simulation was prepared using computer-aided dimensions (CAD) software. After that, the meshing can proceed and follow by settings the boundary condition and other things needed in the setup process. The boundary condition used for this study were mass flow water inlet of $0.506 \mathrm{~kg} / \mathrm{s}$, pressure outlet of $0 \mathrm{~Pa}$, and also the mesh motion feature used for the rotating part. The above wall was set as symmetry, so the boundary layer was not 
occurred near that wall. Figure 3(a) and Figure 3(b) visualized the geometry and mesh used for this numerical study.

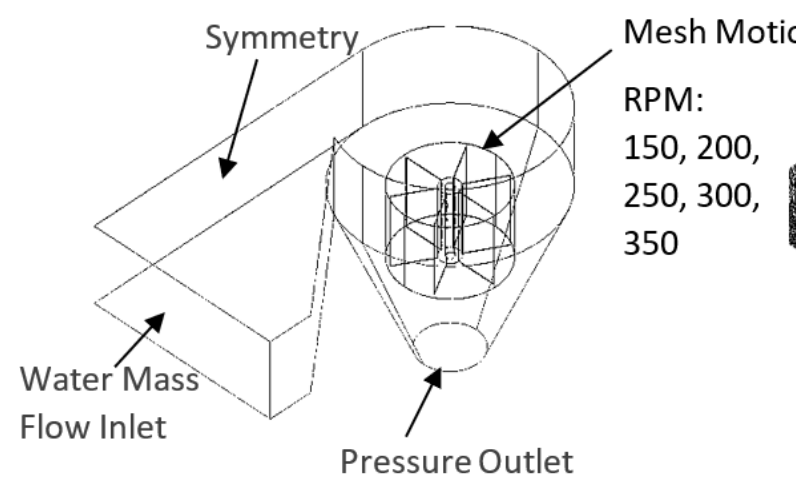

(a)

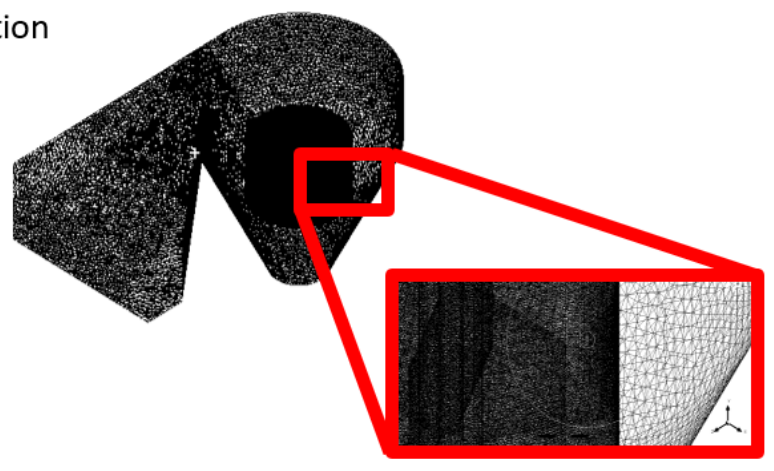

(b)

Fig. 3. (a) Geometry and boundary condition, (b) Visualization of 1,624,787 elements

The simulation was done using transient, single phase, and the turbulence model SST $k-\omega$. This turbulence model was chosen because it can cover a standard bypass flow transition in a low freestream environment [10].

When the simulation could proceed without any difficulties with this setup, the mesh independency test must be performed to verify how much the output parameters result deviated. The mesh independence test was performed using the grid convergency index (GCI) method [12]. The $\mathrm{GCl}$ method was performed using three different numbers of elements; $744,402,1,624,787$, and $3,461,530$ elements. This $\mathrm{GCl}$ was performed in a steady-state condition and frame motion feature. The torque output was compared using this method to calculate the error between the number of elements.

\section{Results and Discussion}

\subsection{Analytical Result}

Using the Eq. (1)-(12), the value of velocity parameters for curved and straight blades can be seen in Table 2. Table 2 also shows the value of hydraulic efficiency for both blades. It can be seen that the hydraulic efficiency for the curved blade is slightly higher than the straight blade. The geometry for the blade can be seen in Figure 4. It can be seen that the curved blade is slightly buckled according to the value of absolute and relative Angle $\left(\alpha_{1}\right),\left(\beta_{1}\right),\left(\beta_{2}\right)$. The thickness chosen for the blades is 0.2 $\mathrm{mm}$ since the geometry for the simulation was scaled $1: 10$, so if the blades are produced, it will have a thickness of $2 \mathrm{~mm}$ plates, which is easy to get (Heller 2012). 


\section{Table 2}

Velocity Parameters for Curved and Straight Blades

\begin{tabular}{ll}
\hline Description & Total \\
\hline Velocity at Inlet $\left(V_{i n}\right)$ & $0.5 \mathrm{~m} / \mathrm{s}$ \\
Tangential Velocity Entering the Blade $\left(U_{1}\right)$ & $0.65 \mathrm{~m} / \mathrm{s}$ \\
Absolute Angle Entering the Blade $\left(\alpha_{1}\right)$ & $9^{\circ}$ \\
Relative Angle Entering the Blade $\left(\beta_{1}\right)$ & $100^{\circ}$ \\
Relative Angle Exiting the Blade $\left(\beta_{2}\right)$ & $76^{\circ}$ \\
Entering Velocity Direct to the Shaft $\left(C_{r 1}\right)$ & $0.10616 \mathrm{~m} / \mathrm{s}$ \\
x-axis Absolute Velocity $\left(V_{x 1}\right)$ & $0.67 \mathrm{~m} / \mathrm{s}$ \\
Tangential Velocity Exiting the Blade $\left(U_{2}\right)$ & $0.13083 \mathrm{~m} / \mathrm{s}$ \\
Exiting Velocity Direct to the Shaft $\left(C_{r 2}\right)$ & $0.53 \mathrm{~m} / \mathrm{s}$ \\
Hydraulic Efficiency Straight Blade $\left(\eta_{H}\right)$ & 0.742 \\
Hydraulic Efficiency Curved Blade $\left(\eta_{H}\right)$ & 0.773 \\
Assumption of Hub-tip Ratio & 0.2 \\
Assumption of Rotational Speed of the Turbine & $250 \mathrm{rpm}$ \\
\hline
\end{tabular}

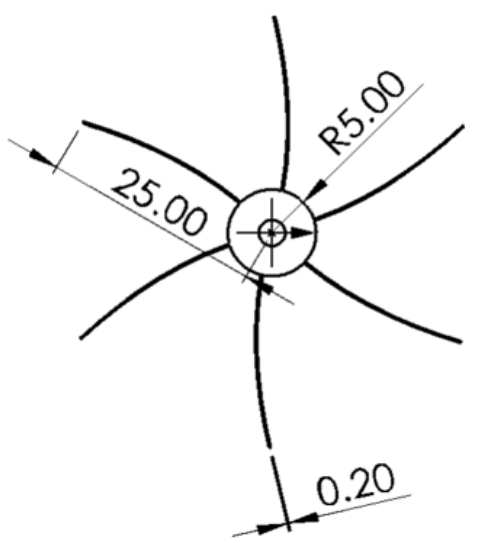

(a)

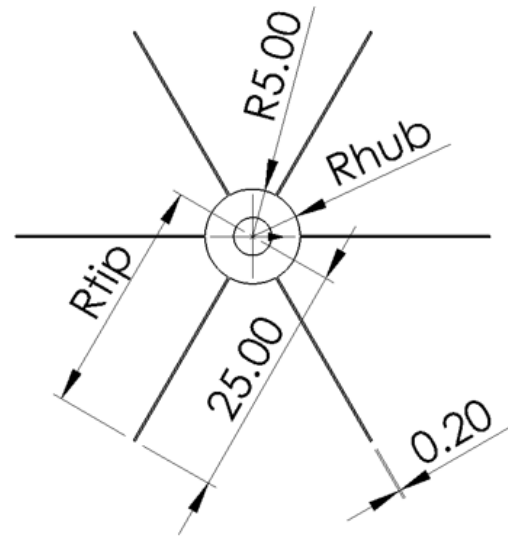

(b)

Fig. 4. (a) Design of Curved Blade, (b) Design of Straight Blade

\subsection{Mesh Independency Test Result}

The mesh independence test was done using Richardson extrapolation and achieved a result of torque of $-0.0102 \mathrm{Nm}$. Table 3 shows that the approximate error for 1,624,787 elements was under $1 \%$. Therefore, this mesh was good enough to be used because the result doesn't deviate much.

Table 3

Mesh Indepedency Table

\begin{tabular}{llllll}
\hline Mesh Number & Grid Spacing & Torque & $\mathrm{r}$ & $\mathrm{P}$ & $\mathrm{GCl}$ \\
\hline 744402 & 1.6691173 & -0.0100604 & - & - & - \\
1624787 & 1.2867393 & -0.0101255 & 1.297168 & 2.396145 & $0.9287 \%$ \\
3461530 & 1 & -0.0101604 & 1.286739 & 2.472867 & $0.4962 \%$ \\
\hline
\end{tabular}

\subsection{Numerical Result}

Figure 5 shows the hydraulic efficiency vs. U/V, where U/V is a ratio between blade tangential velocity and absolute inlet velocity of the curved and straight blade. As Figure 6 shows, it clearly can be seen that the hydraulic efficiency of both the blades very similar to each other. This means that the blade converges the same amount of energy from the available energy from the fluid. This can 
be seen in Figure 6, where the pressure contour of both blade types is very similar. Because of this result, another optimization approach was performed and analyzed how much it affects the hydraulic efficiency.

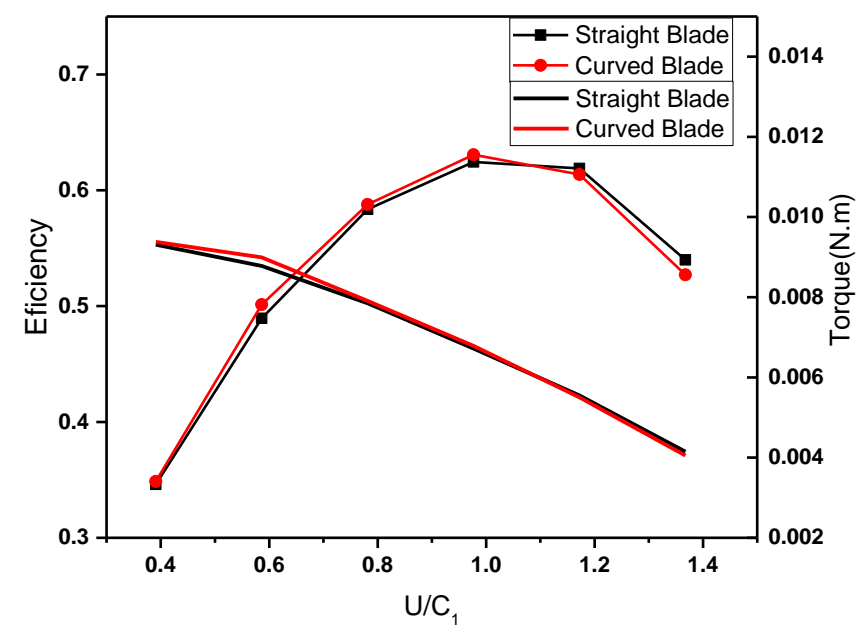

Fig. 5. Graphics U/C vs. Hydraulic efficiency and Torque of Straight and Curved Blade

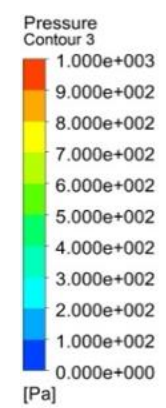

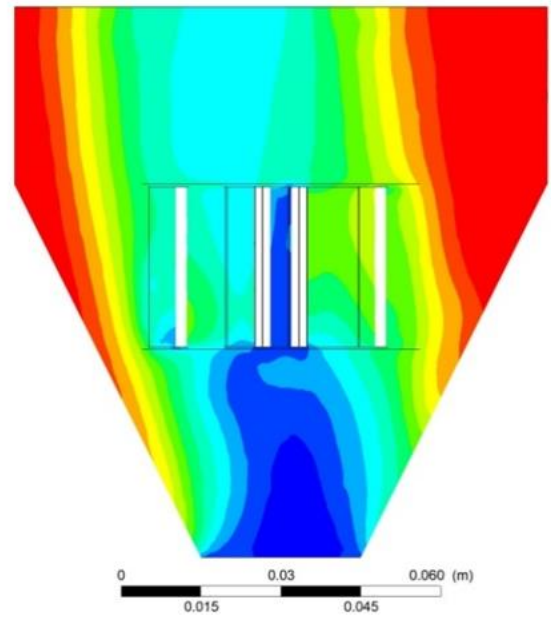

Curved Blade

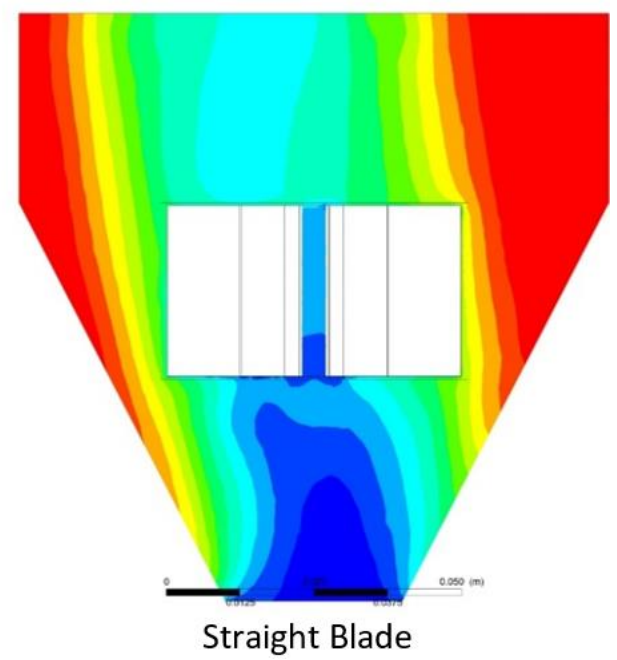

Straight Blade

Fig. 6. Static Pressure at Vertical Section of the Blade

Since the hydraulic efficiency of both blades doesn't differ much from one another, another numerical study was performed changing the T/D parameters, where $T$ is the height from the water surface to the surface of the blade and $D$ is the diameter of the blade which is constant in this study. There will be five different T/D which is $0.1,0.333,0.467,0.667$, and 0.867 . The hydraulic efficiency will be compared each other. Figure 7 is used to visualize the parameters of T/D. 


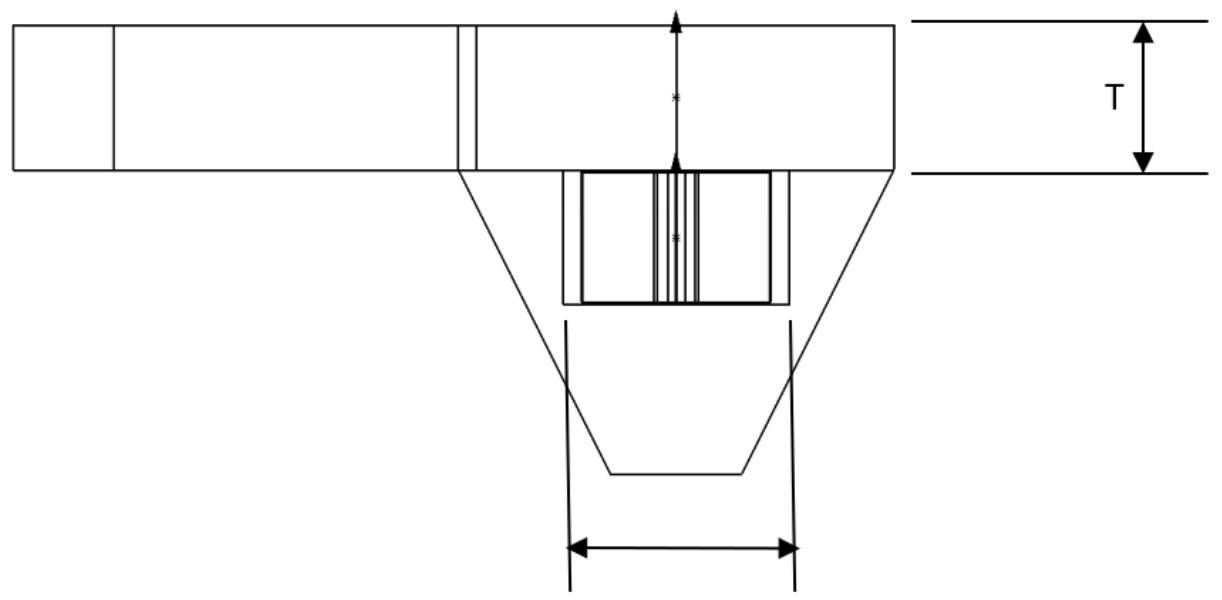

Blade Diameter (D)

Fig. 7. Visualization of T/D Parameter

The result of this simulation can be seen in Figure 8. The graph shows that the highest hydraulic efficiency achieved at T/D 0.333 with a value of 0.84 . This shows that at the T/D 0.333 the blade converged available energy better than other T/D position. This can be seen in Figure 9 which shows the static pressure on the blades. The static pressure on the blades represent that the higher the pressure on the blade means that higher kinetic energy is being converged from the velocity inlet.

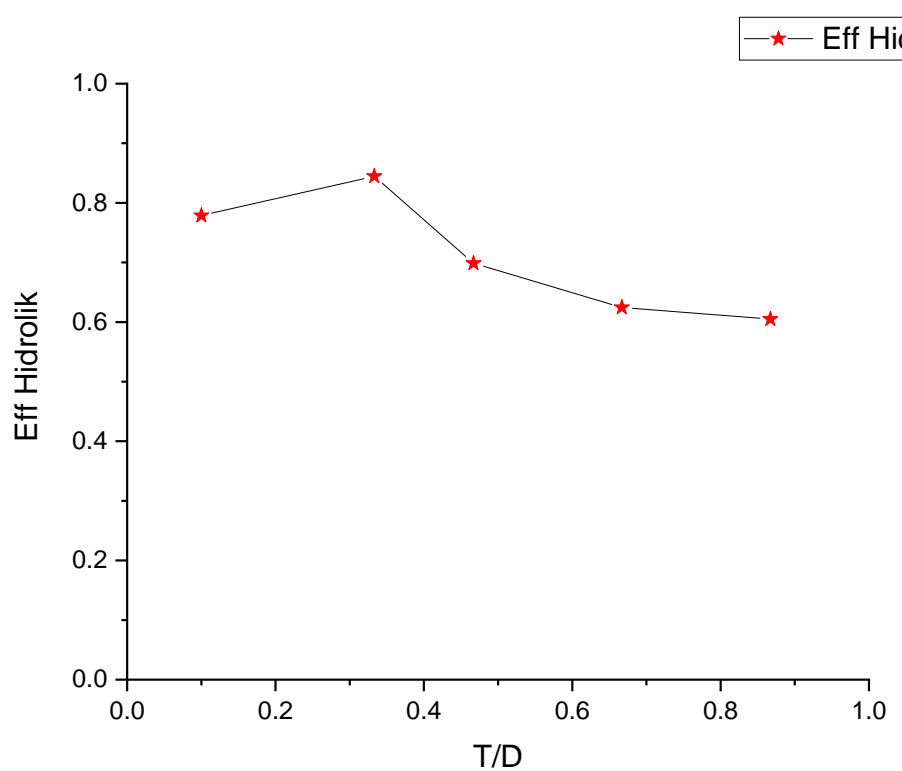

Fig. 8. Graphics T/D vs. Hydraulic Efficiency at 250 RPM 


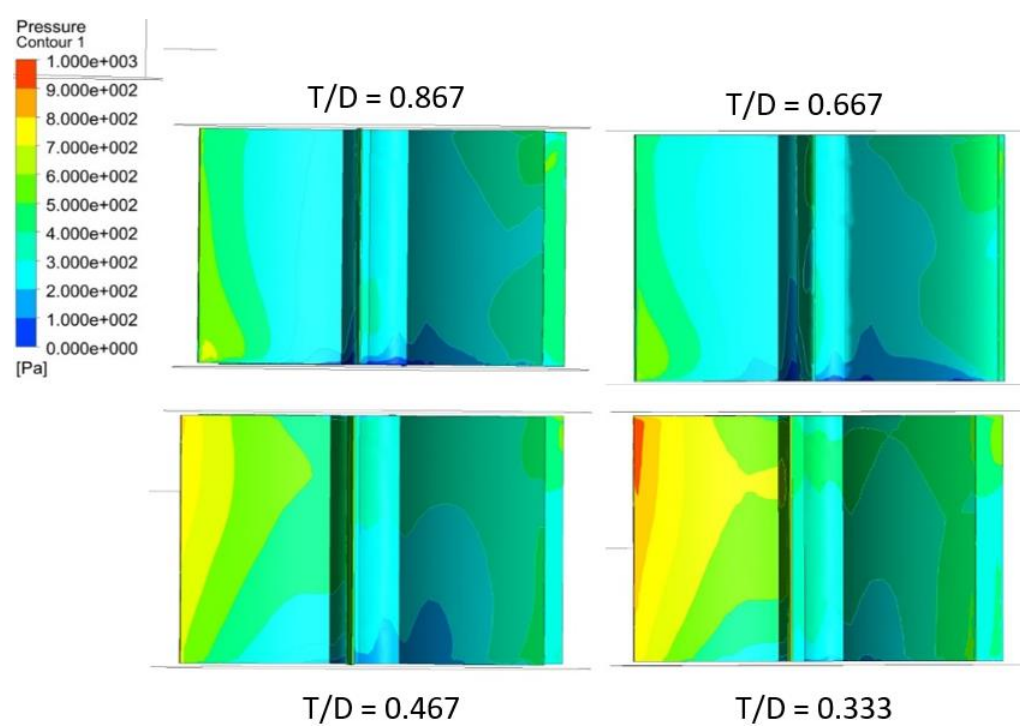

Fig. 9. Static Pressure at the Blade of each T/D

\subsection{Discussion}

From the analytical result, it can be seen that curved blade hydraulic efficiency is slightly higher than the straight blade. This result also similar to the numerical method, although the hydraulic efficiency is lower than the analytical result cause of the simplification of the equation used on the analytical method. In the study by Khan [8], it can be seen that his result quite differs from this study. Khan got a result of curved blade hydraulic efficiency quite lower than the straight blade. This happens because of the buckle angle of the curved blade. His study used a high angle buckled curved blade. It can be seen that the higher the buckled angle the lower the hydraulic efficiency. Figure 10 is an efficiency graph from Khan's study both of numerical and experimental, where Profile 1 is the inverted straight blade and, Profile 3 is the curved blade. So, it is better to use a straight blade because of the simple to manufactured and more efficient rather than a curved blade. In Khan's study, it also showed the power output differences between numerical and experimental results. Table. 4 shows the difference between numerical and experimental power output.

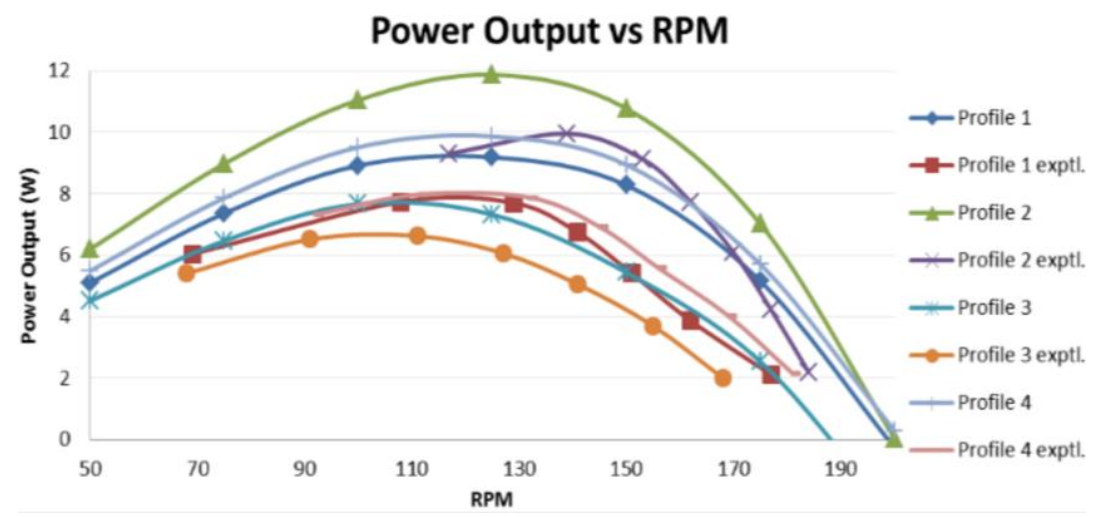

Fig. 10. Power Output vs RPM of Khan's study [8] 
Table 4

Difference between Numerical and Experimental Result [8]

\begin{tabular}{lll}
\hline Blade & $\begin{array}{l}\text { Differences between Numerical and Exp. Results } \\
\text { Efficiency 1 } \\
\text { Efficiency 2 }\end{array}$ \\
\hline Profile 1 & 7.06 & 7.92 \\
Profile 2 & 9.31 & 12.28 \\
Profile 3 & 5.05 & 6.05 \\
Profile 4 & 9.17 & 10.46 \\
\hline
\end{tabular}

Because of the insignificant change of the hydraulic efficiency of both blades, another simulation was done to analyse a correlation between T/D and the hydraulic efficiency. It can be seen from Figure 8 that the T/D parameter is quite significant to the performance of the blades rather than the type of the blades. This T/D parameter affects a lot to the value of the velocity inlet to the blade, and also the vectors. It can be seen from Figure 9 that in every different $T / D$, the momentum conversion on the blade is quite significantly different. Study of Ullah et al., [17] shows that the best T/D condition is at condition $\mathrm{c}$ in his study which can be seen in Figure 11. In condition c, all of the output parameters are at the highest which can be said that it produced the highest efficiency as well [17]. However, the difference between Ullah's study and this study is significantly can be looked at Figure 8. In this study the highest efficiency can be achieved at the condition T/D of 0.333, and when the $T / D$ is 0.1 the efficiency is reduced again, not like in Ullah's study which doesn't analyze in each T/D when the blade is submerged.
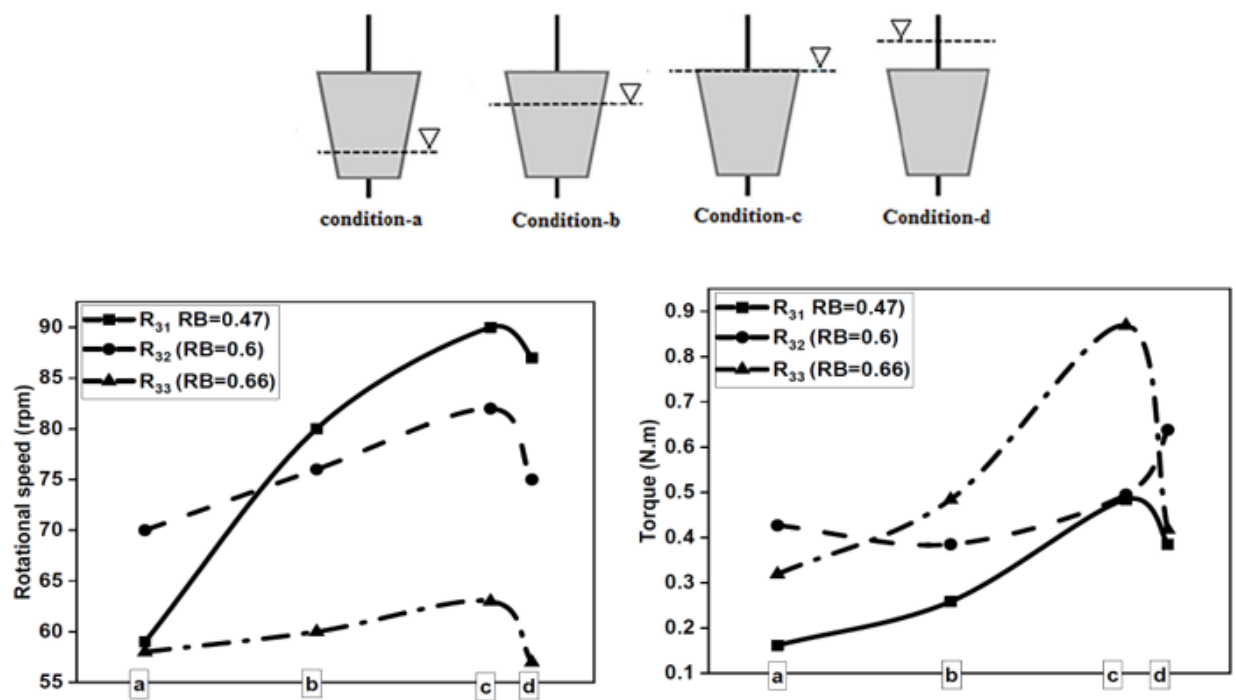

Fig. 11. Condition of Ullah's study and the output results [17]

\section{Conclusions}

This study shows the analytic approached that used for approximating the hydraulic efficiency of the blades. This study also shows the method to calculate the buckled angle for the curved blade. This study concludes that hydraulic efficiency doesn't affect much between straight and curved blades. The curved blade doesn't affect much the velocity vector after hitting the blade. The hydraulic efficiency for those blades is around 0.63 , and with the proper location of the blade, the hydraulic efficiency can reach until 0.84 . This highest hydraulic efficiency can be achieved when the blades positioned at T/D 0.333. In this position, it can be said that the kinetic energy is best converged in this position. This means that the location of the blades is more important than the type of blades, although there must be a really compatible type of blade for gravitational water vortex turbine. 


\section{Acknowledgement}

This work was supported by the Directorate of Research and Service, Community Universitas Indonesia, with grant No: NKB-1127/UN2.RST/HKP.05.00/2020.

\section{References}

[1] Kueh, T. C., S. L. Beh, Y. S. Ooi, and D. G. Rilling. "Experimental study to the influences of rotational speed and blade shape on water vortex turbine performance." In Fifteenth Asian congress of fluid mechanics (15ACFM), Sarawak, Malaysia, pp. 21-24. 2017. https://doi.org/10.1088/1742-6596/822/1/012066

[2] Christopher, C. R., and D. Adanta. "The effect of basin geometry on gravitational vortex hydropower." In IOP Conference Series: Materials Science and Engineering, vol. 788, no. 1, p. 012081. IOP Publishing, 2020. https://doi.org/10.1088/1757-899X/788/1/012081

[3] Dhakal, Subash, Susan Nakarmi, Pikam Pun, Arun Bikram Thapa, and Tri Ratna Bajracharya. "Development and testing of runner and conical basin for gravitational water vortex power plant." Journal of the Institute of Engineering 10, no. 1 (2014): 140-148. https://doi.org/10.3126/jie.v10i1.10895

[4] Dhakal, Sagar, Ashesh Babu Timilsina, Rabin Dhakal, Dinesh Fuyal, Tri Ratna Bajracharya, and Hari Prasad Pandit. "Effect of dominant parameters for conical basin: Gravitational water vortex power plant." In Proceedings of IOE Graduate Conference, p. 381. 2014.

[5] Heller, Valentin. "Model-prototype similarity." 4th Coastlab Teaching School, Wave and Tidal Energy January (2012): 17-20.

[6] Ho-Yan, Bryan. "Design of a low head pico hydro turbine for rural electrification in Cameroon." PhD diss., The University of Guelph, Canada, 2012.

[7] IRENA. "Renewable Energy Prospects: Indonesia, a REmap Analysis." International Renewable Energy Agency (IRENA), Abu Dhabi, 2017.

[8] Khan, Nauman Hanif. "Blade optimization of gravitational water vortex turbine." PhD diss., Tesis MT, Teknik Mesin, Ghulam Ishaq Khan Institute of Engineering Sciences and Technology, 2016.

[9] Marian, Marius Gheorghe, Tudor Sajin, and Abdelkrim Azzouz. "Study of micro hydropower plant operating in gravitational vortex flow mode." In Applied Mechanics and Materials, vol. 371, pp. 601-605. Trans Tech Publications Ltd, 2013. https://doi.org/10.4028/www.scientific.net/AMM.371.601

[10] Mulligan, Sean. "Experimental and numerical analysis of three-dimensional free-surface turbulent vortex flows with strong circulation." Ireland: Institute of Technology Sligo (2015).

[11] Nishi, Yasuyuki, and Terumi Inagaki. "Performance and flow field of a gravitation vortex type water turbine." International Journal of Rotating Machinery 2017 (2017): 1-11. https://doi.org/10.1155/2017/2610508

[12] Phillips, Tyrone S., and Christopher J. Roy. "Richardson extrapolation-based discretization uncertainty estimation for computational fluid dynamics." Journal of Fluids Engineering 136, no. 12 (2014). https://doi.org/10.1115/1.4027353

[13] Rahman, M. M., J. H. Tan, M. T. Fadzlita, and AR Wan Khairul Muzammil. "A Review on the development of Gravitational Water Vortex Power Plant as alternative renewable energy resources." In IOP Conference Series: Materials Science and Engineering, vol. 217, no. 1, p. 012007. IOP Publishing, 2017. https://doi.org/10.1088/1757899X/217/1/012007

[14] Shabara, H. M., O. B. Yaakob, Yasser M. Ahmed, and A. H. Elbatran. "CFD simulation of water gravitation vortex pool flow for mini hydropower plants." Jurnal Teknologi 74, no. 5 (2015): 77-81. https://doi.org/10.11113/jt.v74.4645

[15] Direktorat Jenderal Ketenagalistrikan. "Statistik Ketenagalistrikan T.A. 2017." Kementerian Energi dan Sumber Daya Mineral, 2018.

[16] Timilsina, Ashesh Babu, Sean Mulligan, and Tri Ratna Bajracharya. "Water vortex hydropower technology: a stateof-the-art review of developmental trends." Clean Technologies and Environmental Policy 20, no. 8 (2018): 17371760. https://doi.org/10.1007/s10098-018-1589-0

[17] Ullah, Rizwan, Taqi Ahmad Cheema, Abdul Samad Saleem, Sarvat Mushtaq Ahmad, Javed Ahmad Chattha, and Cheol Woo Park. "Preliminary experimental study on multi-stage gravitational water vortex turbine in a conical basin." Renewable Energy 145 (2020): 2516-2529. https://doi.org/10.1016/i.renene.2019.07.128 